\title{
Ontogenetic habitat associations of a demersal fish species, Pagrus auratus, identified using boosted regression trees
}

\author{
Tanya J. Compton ${ }^{1,4, *}$, Mark A. Morrison ${ }^{2}$, John R. Leathwick ${ }^{1}$, Glen D. Carbines ${ }^{3}$ \\ ${ }^{1}$ National Institute of Water \& Atmospheric Research Ltd., PO Box 1115, Hillcrest, Hamilton 3216, New Zealand \\ ${ }^{2}$ National Institute of Water \& Atmospheric Research Ltd., 41 Market Place, Viaduct Harbour, Auckland 1149, New Zealand \\ ${ }^{3}$ Stock Monitoring Services Ltd., PO Box 89234, North Shore, Auckland 0742, New Zealand \\ ${ }^{4}$ Present address: Marine Ecology, Royal Netherlands Institute for Sea Research, Landsdiep 4, 1797 SZ, 't Horntje, Texel, \\ Netherlands
}

\begin{abstract}
In coastal areas, the identification of habitat types critical to fish life history strategies can provide useful information for ecosystem-based management. Recent studies show that species distribution modelling can be a cost effective tool for describing fish habitat. However, few modelling studies have examined ontogenetic habitat associations. This is critical, as fish species often have different habitat preferences depending on their life stage. In this study, we used boosted regression trees (BRT) to describe ontogenetic habitat associations in snapper Pagrus auratus across the inner Hauraki Gulf of New Zealand. The BRT models identified that juvenile snapper were most frequently associated with slow orbital velocities and slow tidal current speeds, as well as biogenic sedimentary structures (area under the receiver operating curve or AUC, a measure of model performance, 0.79). In contrast, larger snapper were associated with faster tidal currents and faster orbital velocities (AUC 0.78). Juvenile and adult snapper were spatially separated; juvenile snapper occurred in waters close to shore, whereas large snapper occurred mainly in the channels between the islands and the waters around the islands. The successful discrimination of adult and juvenile habitat associations suggests that a modelling approach such as this could be useful for ecosystem-based management.
\end{abstract}

KEY WORDS: Pagrus auratus $\cdot$ Fish $\cdot$ Essential fish habitat $\cdot$ Ecosystem management $\cdot$ Species distribution modelling

Resale or republication not permitted without written consent of the publisher

\section{INTRODUCTION}

In temperate regions, a large percentage of the human population is concentrated along the coast, e.g. $90 \%$ of Australia's population lives on or near the coast (Kingsford \& Battershill 1998). In these highly populated coastal areas, anthropogenic activities can cause habitat degradation in marine environments (Lotze et al. 2006), e.g. recreational fishing (McPhee et al. 2002), benthic disturbance (Watling \& Norse 1998, Thrush \& Dayton 2002), sedimentation (Thrush et al. 2003) and urban run-off (Kemp et al. 2005).
Consequently, fish populations and the habitats that support them are under a range of pressures in highly populated coastal areas (Kingsford \& Battershill 1998). Instead of managing fish populations in isolation from their environment, it is recognized that habitats integral to fish life history strategies need preserving (Pikitch et al. 2004, Armstrong \& FalkPeterson 2008, Valavanis et al. 2008, Palumbi et al. 2009). Thus, in most countries, the identification of essential fish habitat has become a goal for management, e.g. the 1996 amendments of the MagnusonStevens Fisheries and Conservation Management 
Act in the USA. For managers of fisheries and other resources to effectively manage such habitats, it is necessary to develop tools that can identify and map essential fish habitats across operationally relevant spatial scales (Beger \& Possingham 2008).

Species distribution models can be used to explore the association between field observations and environmental variables to produce mapped predictions of fish occurrence (Stoner et al. 2001, Ciannelli et al. 2008, Valavanis et al. 2008, Knudby et al. 2009). A wide range of algorithms is available for species distribution modelling, and these algorithms generally fall into 2 groups: generalized linear models, like generalized additive models; or, more recently, machine learning algorithms, like boosted regression tree analysis and maximum entropy (see review papers Guisan \& Thuiller 2005, Austin 2007, Elith \& Leathwick 2009). Similarly to empirical field experiments (Lirman 1999, Gratwicke \& Speight 2005), species distribution models show that increased fish diversity or abundance can be associated with increased habitat complexity. Examples include the substratum rugosity of reefs (Friedlander \& Parrish 1998, Pittman et al. 2007, Pittman et al. 2009, Knudby et al. 2010, Monk et al. 2010) and biogenic complexity in soft sediments, e.g. rock sole densities relative to worm tube densities and sediment bed-form structure (Stoner et al. 2007).

Investigating ontogenetic relationships in fish should improve our ecological understanding because many fish species display ontogenetic habitat associations (e.g. Werner \& Gilliam 1984, Dahlgren \& Eggleston 2000). However, few modelling studies examine the habitat associations of adult and juvenile fish of the same species (Jeffrey et al. 2010). In a single case, where adult and juvenile life-stages of flounder were modelled using generalized additive models, the models detected that small sizes of flounder occur more frequently in deep depositional environments, whereas adults occur more frequently in organic, rich, shallow waters (Stoner et al. 2001).

In this study, we examined the ontogenetic habitat associations of the sparid Pagrus auratus (snapper, Bloch \& Schneider, 1801), with respect to variables describing its habitat in the inner Hauraki Gulf of New Zealand. Snapper is an important recreational and commercial fish species in New Zealand, Australia and Japan (Kailola et al. 1993). New Zealand's most important snapper fishery area, supporting its largest commercial and recreational fisheries (Francis 1994), is the Hauraki Gulf, a large sedimentary embayment located on the east coast of the North Island of New Zealand $\left(175^{\circ} \mathrm{E}, 36^{\circ} \mathrm{S}\right)$. To identify whether juveniles and adults displayed different habitat associations, we modelled juvenile and adult snapper observations using boosted regression trees (BRT). Based on previous work, we expected that juvenile snapper should be associated with higher sediment complexity in sedimentary habitats (Thrush et al. 2002). To determine whether adult and juvenile snapper had different spatial distributions, we also used the BRT models to map the predicted occurrences of adults and juveniles across the inner Hauraki Gulf. Finally, these spatial predictions were compared to known recreational fishing pressures in the inner Hauraki Gulf. The modelling approach described here for snapper could provide information about what features of the environment are important for fish species. This information could then be utilized as one of many layers of information for marine spatial planning.

\section{MATERIALS AND METHODS}

\section{Field data collection and post-processing}

This study focusses on snapper occurrence in the inner Hauraki Gulf, an area close to the city of Auckland (Fig. 1). Snapper in the inner Hauraki Gulf are fished predominantly by recreational fishers, who remove 400 to $800 \mathrm{t}$ of snapper larger than $27 \mathrm{~cm}$ annually, and to a lesser extent by commercial longliners (trawling is banned from the inner Gulf, and long-lining is only permitted during winter). Core recreational fishing areas include the Rangitoto (between Auckland and Rangitoto Island) and Motuihe channels (between Rangitoto and Waiheke Islands) (Fig. 1). The inner Hauraki Gulf was divided up into 11 spatial strata (see Fig. 1), modified from Hartill et al. (2007), which aimed to encompass the different broad-scale environments in this area, e.g. island sheltered strait, channel areas, an island group and more open exposed waters. Within each stratum, 8 to 15 random towed drop underwater video (DUV) transects, each circa $400 \mathrm{~m}$ in length, were sampled in summer (November and December 2006), autumn (March and April 2007) and winter (June and August 2007). All DUV sampling was conducted during the hours of darkness, when snapper settle on the seafloor and remain inert (sleeping). Standard white light dive torches were used as an illumination source (see Morrison \& Carbines 2006 for more information on the DUV setup). No reactions were seen from the snapper until the DUV was physically almost on top of them, by which time the fish were 

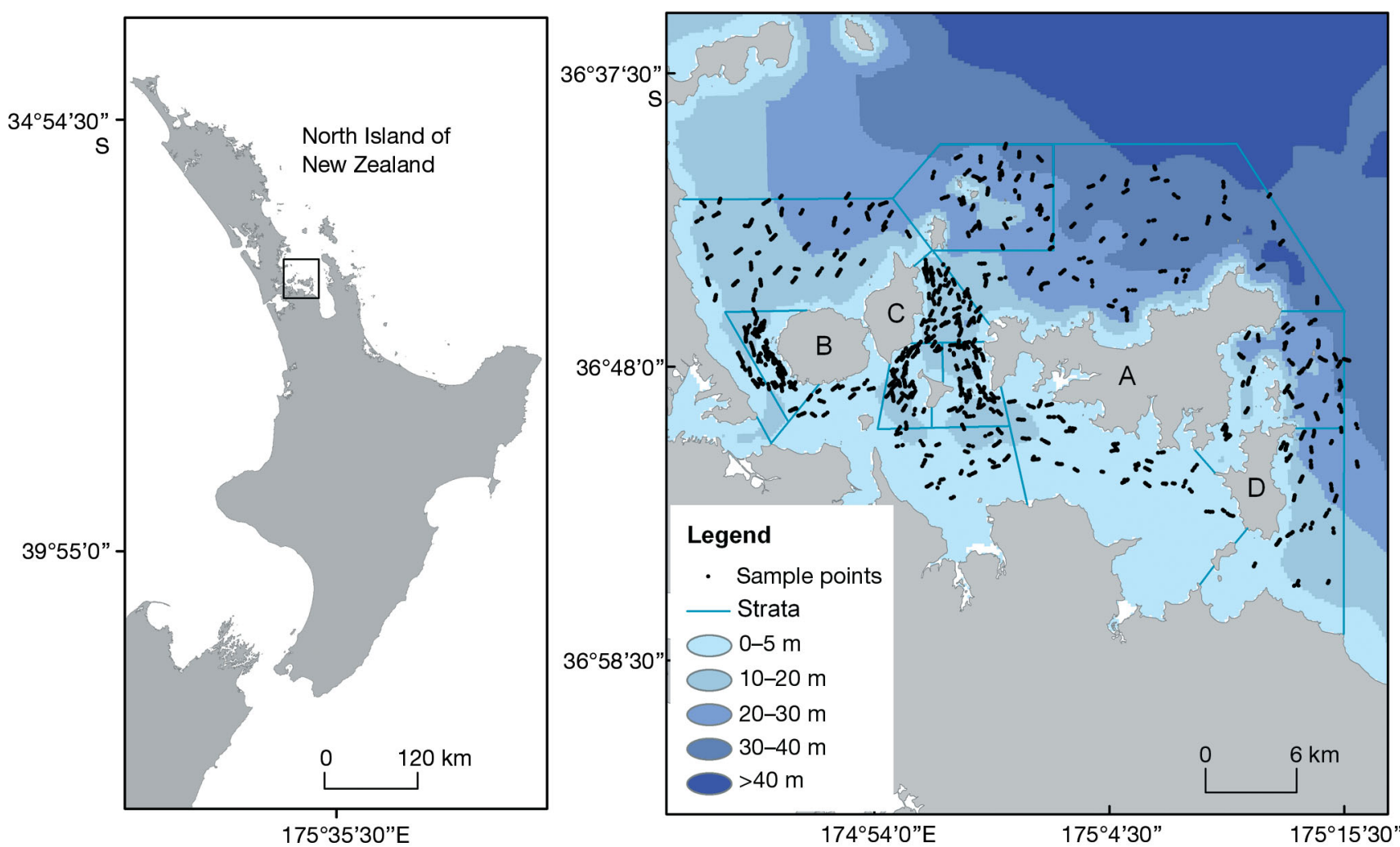

Fig. 1. Location of the inner Hauraki Gulf relative to the North Island of New Zealand, and location of the islands within the inner Hauraki Gulf: (A) Waiheke Island, (B) Rangitoto Island, (C) Motutapu Island and (D) Ponui Island. Sampling points located within the 11 strata and depth intervals in this area are also shown (solid points). White areas indicate no data

'captured' on camera. Many fish did not move at all, and no 'puffs' of sediment were observed without a fish; when fish move off the seafloor they usually disturb it, suggesting that sleeping fish were not missed. Sampling during the day was not possible, as snapper and other species are active and are not vulnerable to being 'captured' by the DUV system. We considered night resting sites to be closely representative of daily habitat use, because tagging studies show that snapper have daily home ranges of $<200 \mathrm{~m}$, and can show high to medium-term site fidelity (Willis et al. 2001, Hartill et al. 2003).

During field data collection, GPS position, time and water depth were automatically recorded onto video tapes using a data titler. Two red light scaling lasers were set horizontally $20 \mathrm{~cm}$ apart and projected forward onto the seafloor, to provide a proportional scaling measure for transect width and the size of objects (fish) seen in the image. Back in the laboratory, each video transect was replayed and fish were counted and identified. Snapper were readily distinguishable from the other fish species present by their shape and colour. For each fish, the image was brought frame by frame into the same field of view as the 2 horizontal lasers, and the fish was measured in relation to this scale $(20 \mathrm{~cm})$. Some measurement error can occur when fish are positioned at angles greater than $20^{\circ}$ to the camera, especially larger fish. Snapper were then defined as juveniles or adults based on age-length relationships known from Kawau Bay, also located in the Hauraki Gulf, New Zealand (Francis 1994). Fish smaller than $15 \mathrm{~cm}$ were classed as juveniles $\left(0^{+}\right.$and $\left.0^{+} / 1^{+}\right)$and fish longer than $15 \mathrm{~cm}$ were defined as adults ( $>1^{+}$, Francis 1994).

For each snapper encountered, a sampling box for recording habitat features was defined: $5 \mathrm{~m}$ forward and $5 \mathrm{~m}$ back from the fish, and to the edges of the video imagery. In each sampling box, sediment evacuations made by fishes and rays (number of pits), burrow openings made by crustaceans (number of burrows) and the number of sediment mounds (mounds) were counted. In addition, operational taxonomic units (OTUs, $>5 \mathrm{~cm}$ ) were counted, i.e. sponges, horse mussels Atrina zelandica, ascidians and anemones. To provide a set of background or pseudoabsence samples, sampling boxes with no fish 
were also randomly selected and analysed. The number of absence sample boxes analysed was equivalent to the number of fish sample boxes. In total 4884 sampling boxes, split between fish sample boxes and absence sample boxes, were analysed in this study.

\section{Environmental data}

Previously developed geo-referenced environmental layers covering the Hauraki Gulf region were used in this study: tidal current speed and orbital velocity (grid size: $200 \mathrm{~m}^{2}$ ) (Snelder et al. 2007). Tidal currents were estimated using an existing hydrodynamic model of the Hauraki Gulf (MIKE 3) (Hadfield et al. 2002). Mean orbital velocity was derived from a simulation using the SWAN shallow-water wave model based on a $20 \mathrm{yr}$ hindcast of wave conditions in the New Zealand region (Hadfield et al. 2002). Although a layer describing the depth of our sampling area was available (Hadfield et al. 2002), preliminary boosted regression tree modelling analyses identified that snapper did not show clear associations with depth, so this variable was excluded. Fishing intensities were taken from a previous study which used aerial surveys to count individual recreational fishing boats, and then interpolated these to provide contours of fishing intensity across the Hauraki Gulf (Hartill et al. 2007).

\section{Analysis}

A boosted regression tree analysis (BRT) (Friedman et al. 2000, Friedman 2001) was used to identify the variables best associated with ontogenetic variation in habitat use and to produce spatial predictions of habitat use across the inner Hauraki Gulf, as these models have advantages for species distribution modelling (Leathwick et al. 2006, De'ath 2007, Elith et al. 2008). Boosted regression tree models are built using an algorithm that combines regression trees and boosting, and can be described as an advanced form of regression, though they originate from machine learning (Friedman et al. 2000). Regression trees automatically fit interactions between variables, can handle missing values, are insensitive to outliers, and can model almost any type of predictor variable; however, they are prone to misclassification. To overcome the deficiencies of regression trees, a boosting algorithm was used. Boosting improves model performance by focussing on the observations that are hardest to predict with a sequential model fitting process and by adding a probabilistic component to optimize predictive performance. The boosting algorithm is optimized with 2 parameters: learning rate (lr) and tree complexity (tc) (Elith et al. 2008). The learning rate emphasizes unexplained residual variation during tree building, and tree complexity estimates interactions between the predictor variables.

To identify the predictor variables best associated with snapper age, we ran 2 separate models that examined adult or juvenile snapper occurrence with respect to the sampling month, epibenthic diversity, sedimentary structure, tidal current speed, orbital velocity and transect width. Variables are summarized in Table 1. The variable sediment structure (structure) was obtained by summing the number of mounds, burrows and pits at a sample point. In addition, epibenthic diversity (div) was estimated by summing the occurrence of OTUs at each sample point. In each model, the sampled background or pseudoabsence samples and the records from the age group not of interest were used as background samples. When fitting the juvenile or adult models, the background samples were down-weighted such that their sum equalled the sum of the weights for the presence observations (mimicking a prevalence of 0.5) (Guisan et al. 2007).

Both BRT models were assessed using crossvalidated measures of model performance (Elith et al. 2008). Model performance measures included the null deviance, explained deviance and the area under the receiver operating curve (AUC) (Hanley \& McNeil 1982). The explained deviance provides a measure of the goodness-of-fit between the predicted and raw values (total deviance). The AUC assesses the degree to which the fitted values discriminate the observed presences and absences, i.e. a value of 1 indicates that the presences and absences are perfectly discriminated, while a value of 0.5 indicates that discrimination is random (Elith et al. 2006). The importance of each predictor variable was assessed using a script (Ridgeway 2006) that calculates the contribution of each predictor variable to the variance explained in each model. To plot the association between snapper length and a selected predictor variable, for each BRT model, the other predictor variables were held at their means. Optima for adults and juveniles were determined by estimating the weighted mean of each of the predictors with respect to the fitted values.

Spatial predictions of adult and juvenile snapper occurrence were produced across the sampled area 
Table 1. Description of each variable. The range of values that were measured during the survey are given (max. to min.). The source column indicates where the variable was sourced from, i.e. dropped underwater video camera (DUV) or the marine environment classification (MEC) (Snelder et al. 2007, Hadfield et al. 2002). OTU: operational taxonomic unit

\begin{tabular}{|c|c|c|c|}
\hline Variable & Description & Range & Source \\
\hline Orbital velocity & Orbital velocity at the seabed calculated from a $20 \mathrm{yr}$ wave hindcast & $0.5-21.6 \mathrm{dm} \mathrm{s}^{-1}$ & MEC \\
\hline Transect width & $\begin{array}{l}\text { The transect width }(\mathrm{cm}) \text {, or camera frame, for each dropped underwater } \\
\text { video tow sampling box }\end{array}$ & $20.8-432 \mathrm{~cm}$ & DUV \\
\hline Depth & $\begin{array}{l}\text { Depth }(\mathrm{m}) \text { as measured by the dropped underwater video (corrected for } \\
\text { tide) and estimated for the Hauraki marine environment classification }\end{array}$ & $5-42 \mathrm{~m}$ & DUV \\
\hline $\begin{array}{l}\text { Tidal current } \\
\text { speed }\end{array}$ & $\begin{array}{l}\text { Depth averaged maximum tidal current speed derived from a } \\
\text { hydrodynamic model }\end{array}$ & $0.02-0.94 \mathrm{~cm} \mathrm{~s}^{-1}$ & $\begin{array}{l}\text { DUV and } \\
\text { MEC }\end{array}$ \\
\hline $\begin{array}{r}\text { Epibenthic } \\
\text { diversity }\end{array}$ & $\begin{array}{l}\text { Total number of epibenthic OTUs including sponges, horse mussels } \\
\text { Atrina zelandica, ascidians and anemones, but excluding other fish species }\end{array}$ & 0-7 OTU & MEC \\
\hline Structure & $\begin{array}{l}\text { Number of mounds, pits and burrow openings made by benthic } \\
\text { organisms, e.g. crustaceans, fishes and rays. Benthic structures } \\
\text { were grouped as: } 0-1(1), 1-2(2),>2(3)\end{array}$ & $0-3$ & DUV \\
\hline Month & $\begin{array}{l}\text { Sampling month: November (11), December (12), March (3), April (4) } \\
\text { and June (6) and August (8) }\end{array}$ & & \\
\hline
\end{tabular}

in the inner Hauraki Gulf using the adult and juvenile models and the gridded layers $\left(200 \mathrm{~m}^{2}\right.$ grid squares). Where gridded layers for diversity and sediment structure were unavailable, we produced interpolations of diversity and structure across our study area using an inverse distance weighting interpolation (ArcGIS 9.2). However, the variables transect width and month were held at a constant value: for transect width, the mean value for each age class; and for month, the highest fitted model value for a particular month (also see Leathwick et al. 2006). To provide an estimate of mapped prediction error, the models were run repeatedly $(\mathrm{n}=200)$ using bootstrap samples of the data. The 5- and 95-percentile values for each grid cell were estimated as a confidence interval measure around the predictions and mapped. All analyses were conducted in R ( $\mathrm{R}$ Development Core Team 2011 version 2.12), using gbm package version 1.5-7 (Ridgeway 2006) and code that is available online (Elith et al. 2008).

\section{RESULTS}

In total, 844 juvenile $\left(<2^{+}\right)$and 1190 adult snapper were captured on camera. Juveniles were most frequently sampled by camera in June ( $\mathrm{n}=430)$, whereas adults were most frequently sampled in March $(n=340)$. Juvenile snapper tended to be associated with slower orbital velocities, slower tidal current speeds and sedimentary structures, whereas the larger snapper tended to be associated with faster tidal currents and orbital velocities (Fig. 2).
The BRT models gave further insights into how the distribution of snapper varied with respect to the predictor variables, and how this relationship varied with sampling month (Fig. 2). The BRT model results from the juvenile snapper had good model performance (cross-validated AUC 0.79) and identified that the variables describing the physical environment explained $37 \%$ (Table 2) of the total explained model variation $(21 \%)$ (Table 1$)$. These variables were tidal current speed $(21 \%)$ and orbital velocity $(16 \%)$, followed by sediment structure $(29 \%)$ and month of sampling (23\%) (Table 3). Juvenile snapper were most frequently captured with small transect widths (optimum: $116 \mathrm{~cm}$ ) in the months of March, April and June (Fig. 2). Although the probability of occurrence differed among months, the fitted response curves showed that the juvenile snapper were consistently associated with relatively slow tidal current speeds (optimum: $0.19 \mathrm{~cm} \mathrm{~s}^{-1}$ ) and slow orbital velocities (optimum: $3.52 \mathrm{dm} \mathrm{s}^{-1}$ ). Juvenile snapper also tended to be observed in the vicinity of sediment structures (optimum: 4.75 structures). The juvenile model and the gridded environmental layers predicted that the distribution of juvenile snapper would be restricted, with the highest probabilities of occurrence south of the islands and just north of the islands ( $p>0.6)$ and the lowest probabilities in the island channels $(p<0.2)$ (Fig. 3a). The $95 \%$ confidence intervals showed that the largest variation in the predicted probabilities occurred in waters close to the mainland or islands, and also in waters north of the islands (intervals greater than 0.2) (Fig. 3c). 

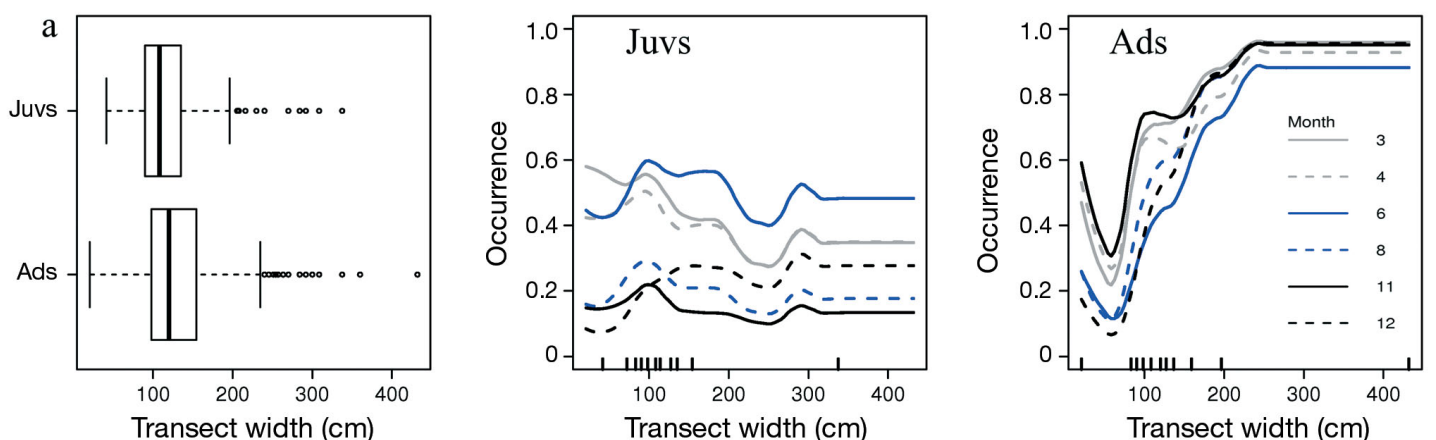

Transect width $(\mathrm{cm})$
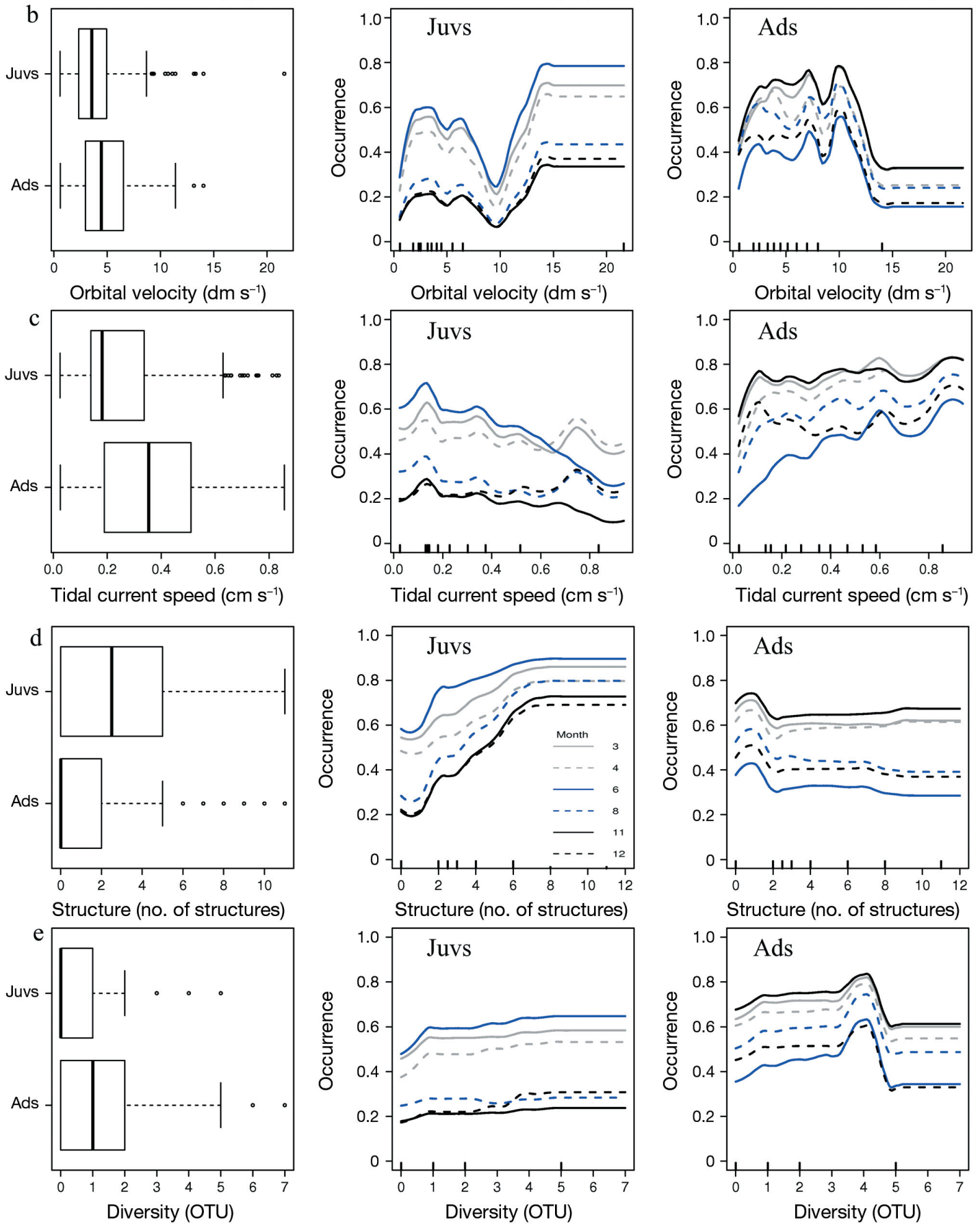
Fig. 2. The raw data distributions and fitted probabilities of occurrence for juvenile (Juvs) and adult (Ads) snapper with respect to (a) transect width, (b) orbital velocity, (c) tidal current speed, (d) sediment structure and (e) epibenthic diversity. Values for each variable were fitted from the boosted regression tree models, while holding the values of the other variables at their means. The positive observations for adults and juveniles are represented as deciles along the bottom of the $x$-axis. Boxes show the interquartile range of the data (first quartile, median and third quartile); the whiskers show values that extend to 1.5 times the interquartile range and small circles indicate outliers. Definitions of variables are given in Table 1

The BRT model from the adult snapper performed well (cvAUC 0.78) and identified that the variables describing the physical environment, i.e. orbital velocity $(24 \%)$ and tidal current speed (20\%), explained $44 \%$ of the total explained model variation $(17 \%)$ (Tables $2 \& 3)$. Other variables of importance were transect width $(27 \%)$ and month of sampling (19\%) (Table 3). The adult snapper were most frequently captured with a large transect width (optimum: $155 \mathrm{~cm}$ ), in the months of November and March, and had the lowest probability of capture in June (Fig. 2). The fitted responses from the adult snapper model identified that adult snapper were generally associated with faster orbital velocities (optimum: $5.31 \mathrm{dm} \mathrm{s}^{-1}$ ) and tidal current speeds (optimum: $0.37 \mathrm{~cm} \mathrm{~s}^{-1}$ ) than juvenile snapper (see Fig. 2a). Although benthic diversity explained a small amount of variation in the total model $(5 \%)$, the response curves also showed that adult snapper tended to be associated with high benthic diversity (optimum: 1.15 OTU) (Fig. 2). Across the inner Hauraki Gulf, adult snapper were predicted to have a widespread distribution around the islands and between the channels of the islands ( $p>0.6$ ) (Fig. 3b). Probabilities were lower in some areas just south and north of the islands $(p<0.6)$ (Fig. 3b). The confidence intervals around the predicted probabilities were relatively large in waters around the islands (intervals of 0.4 to 0.8 around the mean value of predicted occurrence).

Table 2. Cross-validated estimates of model performance for the boosted regression tree (BRT) models for adult and juvenile snapper. Both models were fitted with a tree complexity of 4 and a learning rate of 0.02 . Model performance was assessed using cross-validated (cv) measures of explained deviance (cvDev) $\pm \mathrm{SE}$, the percentage of the total deviance explained (\%) and the AUC (area under the receiver operating curve) (cvAUC) \pm SE. The null deviance (nulldev), the number of trees (ntrees) used to obtain the BRT model results and the number of positive observations (pres) for adults and juveniles are shown

\begin{tabular}{|lrrrcrl|}
\hline Age & pres & ntrees & nulldev & cvDev \pm SE & $\%$ & cvAUC \pm SE \\
\hline Juveniles & 844 & 800 & 0.48 & $0.10 \pm 0.011$ & 21 & $0.79 \pm 0.008$ \\
Adults & 1190 & 1600 & 0.68 & $0.12 \pm 0.014$ & 17 & $0.78 \pm 0.010$ \\
\hline
\end{tabular}

Table 3. Contributions (\%) of predictor variables to explaining the variation in the adult and juvenile snapper BRT models. The variables with the largest contribution are in bold

\begin{tabular}{|lcc|}
\hline & Juveniles & Adults \\
\hline Tidal current speed & 21 & 20 \\
Month & 23 & 19 \\
Structure & $\mathbf{2 9}$ & 5 \\
Orbital velocity & 16 & 24 \\
Transect width & 8 & $\mathbf{2 7}$ \\
Epibenthic diversity & 4 & 4 \\
\hline
\end{tabular}

\section{DISCUSSION}

In this study, a BRT modelling approach predicted ontogenetic habitat preferences of snapper Pagrus auratus in the inner Hauraki Gulf of New Zealand. Juvenile snapper were most frequently associated with slow orbital velocities and tidal current speeds, and occurred in the vicinity of sedimentary structures, like mounds, pits and burrows, whereas adult snapper were associated with fast tidal current, fast orbital velocities and higher epibenthic diversity. Furthermore, although sampling month was an important predictor variable in these models, the overall repeatability in the shape of the fitted functions among sampling months suggests that the identified habitat associations of adult and juvenile snapper were relatively stable over time across the inner Hauraki Gulf.

The highest absolute numbers of juvenile snapper were seen on camera in June, and the highest numbers of adults were seen in March. The 2 models also identified that the months with the highest fitted probabilities of occurrence were March, April and June for juveniles, and March and November for adults. The increased probability of observing juvenile snapper in March, April and June is likely to be indicative of an improved ability to detect the growing snapper by the DUV camera after 

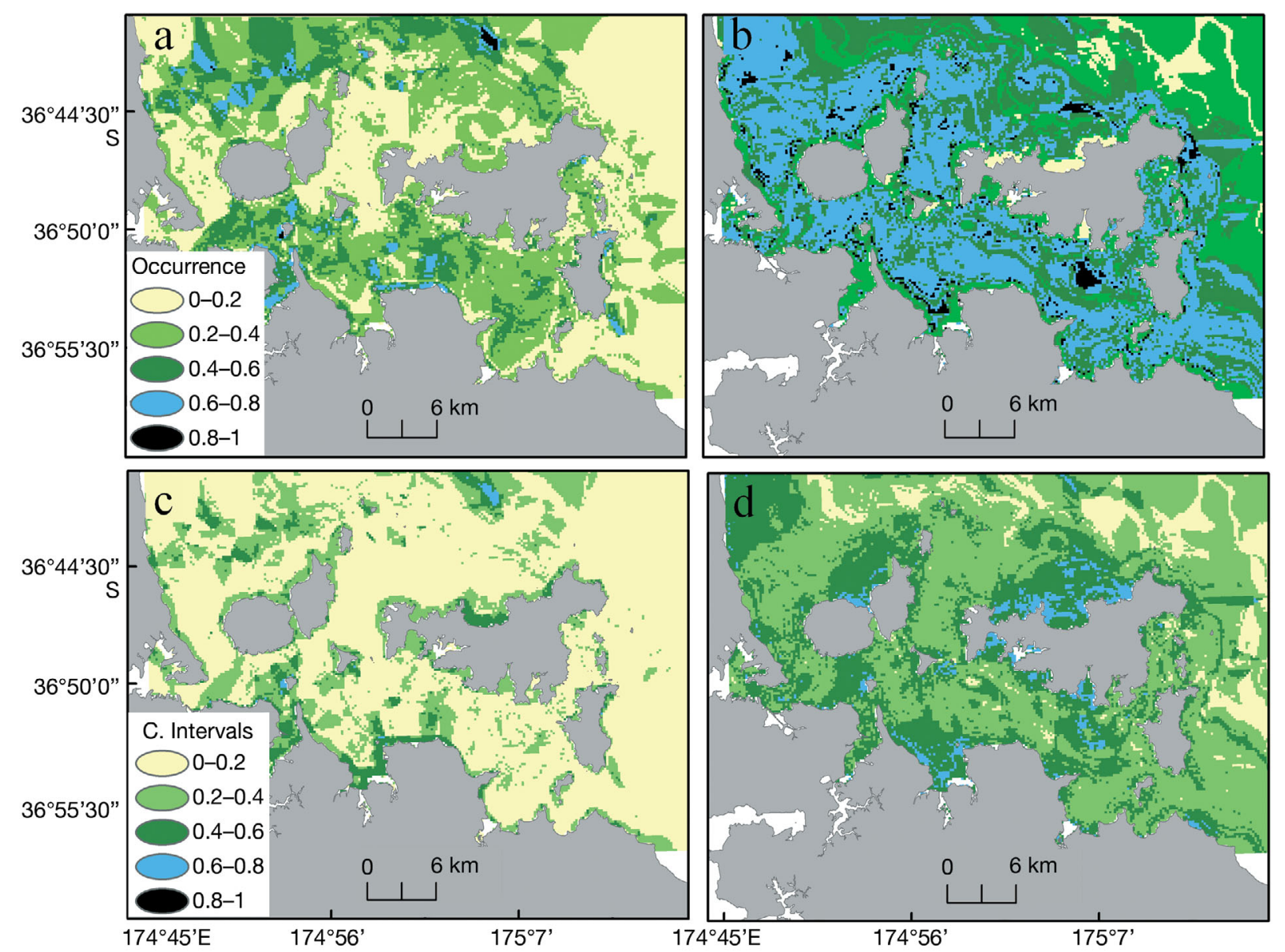

Fig. 3. (a) Juvenile and (b) adult snapper occurrence across the inner Hauraki Gulf, as predicted from the 2 BRT models and the gridded predictor variables. The mapped range in confidence intervals (5 to $95 \%$ ) for the (c) juvenile and (d) adult model predictions were estimated from 200 models fitted to bootstrap samples of the data. Transect width was held at the respective mean values for observing juveniles and adults, while month was held at its maximum value for observing juveniles (June) and the maximum value for observing adults (November). White areas indicate no data

summer, when juvenile snapper first recruit to the inner Hauraki Gulf area (Morrison et al. 2001). The reason that juvenile snapper are not detected by the camera in summer is that they are too small; the DUV has a detection limit of $5 \mathrm{~cm}$ (Morrison \& Carbines 2006). In concordance with the knowledge that adult snapper move closer inshore during summer (Crossland 1982, Parsons et al. 2011), the fitted prediction probabilities for adult snapper were highest during the summer months.

In this study, the tidal current speed and orbital velocity combined provided the greatest explanatory power to both the adult and juvenile models, while the variables describing benthic diversity and sediment structure had a relatively smaller explanatory power. A likely explanation for these results is that although diversity and biogenic sediment structure were not directly correlated with the physical vari- ables, their distribution is likely to be shaped by the physical variables. In other words, the biological variables appear to be nested attributes of the physical variables, e.g. orbital velocities cause bed stress and resuspension of bed material and can structure benthic communities (Warwick \& Uncles 1980). Another aspect that could determine the relative influence of variables like diversity and sediment structure is the spatial scale of the study; if this study had been conducted across a finer spatial scale, the influence of the physical variables might not have been detected, and the other finer-scale variables might have played a larger role in the models.

Although the relative explanatory power of the physical and biologically-mediated variables differed, there was congruence in the habitat associations described by the response curves. The juvenile snapper tended to occur where orbital velocities and 
tidal current speeds were low. These conditions are also ideal for maintaining biogenic sedimentary structures and not washing them away. Thus, our results concur with previous studies which showed that juvenile snapper were most frequently associated with complex sediment features like soft sediment burrows and mounds at smaller spatial scales (Thrush et al. 2002). The reasons why juvenile snapper may prefer these less physically dynamic locations are unknown; however, some reasons may be that there is high abundance of food for juvenile snapper on the substrates, e.g. small amphipods, ostracods and polychaetes (Usmar 2009), and/ or that biologically-mediated habitats provide a refuge from predators (Lindholm et al. 1999, Laurel et al. 2003, Ross et al. 2007). In contrast to small snapper, larger snapper favoured areas of fast orbital velocities, tidal current speeds and high epibenthic diversity. Areas with fast tidal currents could be preferred habitat if they provide high food abundances for larger snapper, e.g. Mysidae and Caridea (Usmar 2009). Alternatively, higher tidal current speed areas may also provide an energetically favourable environment for sleeping, as snapper might save energy by reducing their mobility while still obtaining enough oxygen for respiration.

Transect width played a relatively large role in explaining probability of adult snapper occurrence, as there was an increased chance of counting more adult snapper when the dropped underwater video (DUV) camera was further away from the sediment. In contrast, smaller transect widths were associated with an increased probability of capturing juvenile snapper on camera. The inclusion of transect width into our 2 BRT models took this sampling artifact into account when determining the fitted relationships between snapper and their environment.

Spatial predictions of juvenile and adult habitat associations from the BRT models showed that juvenile snapper tended to be spatially separated from adult snapper across the inner Hauraki Gulf, but that adult snapper also tended to occur in areas predicted to be more frequently inhabited by juveniles. Juvenile snapper did not occur in the channels of high tidal current speed, but were predicted to occur around the islands, mainly where burrows, mounds and pits characterize the sediment. A possible reason for spatial separation is that juveniles are cannibalized by larger snapper, as observed via gut contents analysis (M. Morrison, unpubl. data). Alternatively, juvenile snapper may be avoiding other known predators like John Dory (Zeus faber) and kahawai (Arripus trutta, M. Morrison, pers. obs.). In contrast, larger snapper were predicted to occur in and around the channels of Rangitoto and Waiheke Islands. This widespread distribution matches the recreational fishing pressure in this area (see Appendix 1). The different habitat associations observed in juvenile and adult snapper suggest that decision makers need to consider habitat requirements of the entire life cycle (Pittman \& McAlpine 2003).

This study examined complex variable interactions with respect to fish age in a well studied species (Francis 1994). In the case of less well studied species, or even the same species but in different locations, a size cut-off indicating changes in fish behaviour with age may become arbitrary. Identifying within a single model the age or size at which ontogenetic habitat associations change represents a challenge for future studies across many less well studied marine species.

Ontogenetic habitat associations have been observed in numerous field and laboratory experiments in fish (Green 1996, Fulton \& Bellwood 2002, Lecchini \& Galzin 2005, Laurel et al. 2009); here, we have shown that boosted regression tree analysis can describe and predict ontogenetic habitat associations of snapper at large spatial scales. This study has wide applicability for expansion into other snapper populations, as well as for the examination of ontogenetic habitat associations of fish in general. Ultimately, the fish and habitat distribution maps generated by such models can be used as key inputs for marine spatial planning.

Acknowledgements. We thank B. Venables, P. Dunstan, F. Oehler and T. Diettrich for helpful comments on the statistics and modelling, M. Hadfield and R. Gorman for providing the physical variables, U. Shankar for providing GIS support, D. Parsons, N. Usmar, M. Rijkenberg and J. Hewitt for useful contributions to the manuscript and N. Lewis of the vessel 'Team Effort' for many nights of work in the field. This work was funded by New Zealand Ministry of Science and Innovation programmes CO1X0506 and CO1X0907. We thank 2 referees for their useful comments on this paper.

\section{LITERATURE CITED}

Armstrong CW, Falk-Peterson J (2008) Food for thoughtHabitat-fisheries interactions - a missing link? ICES J Mar Sci 65:817-821

Austin M (2007) Species distribution models and ecological theory: a critical assessment and some possible new approaches. Ecol Model 200:1-19

Beger M, Possingham HP (2008) Environmental factors that influence the distribution of coral reef fishes: modeling occurrence data for broad-scale conservation and management. Mar Ecol Prog Ser 361:1-13 
Ciannelli L, Fauchald P, Chan KS, Agostini VN, Dingsor GE (2008) Spatial fisheries ecology: recent progress and future prospects. J Mar Syst 71:223-236

Crossland J (1982). Movements of tagged snapper in the Hauraki Gulf. NZ Fish Res Div Occasional Publ No 35, Ministry for Primary Industries, Wellington

Dahlgren CP, Eggleston DB (2000) Ecological processes underlying ontogenetic habitat shifts in a coral reef fish. Ecology 81:2227-2240

$>$ De'ath G (2007) Boosted trees for ecological modeling and prediction. Ecology 88:243-251

Elith J, Leathwick JR (2009) Species distribution models: ecological explanation and prediction across space and time. Annu Rev Ecol Syst 40:677-697

Elith J, Graham CH, Anderson RP, Dudik M and others (2006) Novel methods improve prediction of species' distributions from occurrence data. Ecography 29:129-151

- Elith J, Leathwick JR, Hastie T (2008) A working guide to boosted regression trees. J Anim Ecol 77:802-813

> Francis MP (1994) Growth of juvenile snapper, Pagrus auratus. NZ J Mar Freshw Res 28:201-218

> Friedlander AM, Parrish JD (1998) Habitat characteristics affecting fish assemblages on a Hawaiian coral reef. J Exp Mar Biol Ecol 224:1-30

> Friedman JH (2001) Greedy function approximation: a gradient boosting machine. Ann Stat 29:1189-1232

> Friedman JH, Hastie T, Tibshirani T (2000) Additive logistic regression: a statistical view of boosting. Ann Stat 28: 337-407

Fulton CJ, Bellwood DR (2002) Ontogenetic habitat use in labrid fishes: an ecomorphological perspective. Mar Ecol Prog Ser 236:255-262

> Gratwicke B, Speight MR (2005) Effects of habitat complexity on Caribbean marine fish assemblages. Mar Ecol Prog Ser 292:301-310

- Green AL (1996) Spatial, temporal and ontogenetic patterns of habitat use by coral reef fishes (family Labridae). Mar Ecol Prog Ser 133:1-11

Guisan A, Thuiller W (2005) Predicting species distribution: offering more than simple habitat models. Ecol Lett 8: 993-1009

Guisan A, Zimmermann NE, Elith J, Graham CH, Phillips S, Peterson AT (2007) What matters for predicting the occurrences of trees: techniques, data, or species' characteristics? Ecol Monogr 77:615-630

Hadfield M, Uddstrom M, Goring D, Gorman R and others (2002) Physical variables for the New Zealand marine environment classification system: development and description of data layers. Report MFE01517, Ministry for the Environment, Wellington

> Hanley JA, McNeil BJ (1982) The meaning and use of the area under a receiver operating characteristic (ROC) curve. Radiology 143:29-36

Hartill BW, Morrison MA, Smith MD, Boubee J, Parsons DM (2003) Diurnal and tidal movements of snapper (Pagrus auratus, Sparidae) in an estuarine environment. Mar Freshw Res 54:931-940

Hartill B, Bian R, Armiger H, Vaughan M, Rush N (2007) Recreational marine harvest estimates of snapper, kahawai and kingfish in QMA 1 in 2004-05. New Zealand Fisheries Assessment Report 2007/26, Ministry for Primary Industries, Wellington

Jeffrey CFG, Clark R, Hile SD (2010) Spatial patterns in benthic composition of nearshore seascapes and implications for scarid populations and fisheries in La Parguera, SW
Puerto Rico. Proc 62nd Gulf and Caribbean Fisheries Institute, Nov 2-6, 2009, Cumana, p 37-53

Kailola PJ, Williams MJ, Stewart PC, Reichelt RE, McNee A, Grieve C (1993) Australian fisheries resources. Department of Primary Industries and Energy, Canberra

Kemp WM, Boynton WR, Adolf JE, Boesch DF and others (2005) Eutrophication of Chesapeake Bay: historical trends and ecological interactions. Mar Ecol Prog Ser 303:1-29

Kingsford M, Battershill C (1998) Studying temperate marine environments. A handbook for ecologists. Canterbury University Press, Christchurch

Knudby A, Brenning A, LeDrew E (2010) New approaches to modelling fish-habitat relationships. Ecol Model 221: 503-511

Knudby A, LeDrew E, Brenning A (2010) Predictive mapping of reef fish species richness, diversity and biomass in Zanzibar using IKONOS imagery and machinelearning techniques. Remote Sens Environ 114:1230-1241

> Laurel BJ, Gregory RS, Brown JA (2003) Predator distribution and habitat patch area determine predation rates on Age-0 juvenile cod Gadus spp. Mar Ecol Prog Ser 251: 245-254

> Laurel BJ, Ryer CH, Knoth B, Stoner AW (2009) Temporal and ontogenetic shifts in habitat use of juvenile Pacific cod (Gadus macrocephalus). J Exp Mar Biol Ecol 377: 28-35

> Leathwick JR, Elith J, Francis MP, Hastie T, Taylor P (2006) Variation in demersal fish species richness in the oceans surrounding New Zealand: an analysis using boosted regression trees. Mar Ecol Prog Ser 321:267-281

> Lecchini D, Galzin R (2005) Spatial repartition and ontogenetic shifts in habitat use by coral reef fishes (Moorea, French Polynesia). Mar Biol 147:47-58

> Lindholm JB, Auster PJ, Kaufman LS (1999) Habitatmediated survivorship of juvenile (0-year) Atlantic cod Gadus morhua. Mar Ecol Prog Ser 180:247-255

Lirman D (1999) Reef fish communities associated with Acropora palmata: relationships to benthic attributes. Bull Mar Sci 65:235-252

> Lotze HK, Lenihan HS, Bourque BJ, Bradbury RH and others (2006) Depletion, degradation and recovery potential of estuaries and coastal seas. Science 312:1806-1809

McPhee DP, Leadbitter D, Skilleter GA (2002) Swallowing the bait: is recreational fishing in Australia ecologically sustainable? Pac Conserv Biol 8:40-51

Monk J, Ierodiaconou D, Versace VL, Bellgrove A and others (2010) Habitat suitability for marine fishes using presence-only modelling and multibeam sonar. Mar Ecol Prog Ser 420:157-174

Morrison M, Carbines G (2006) Estimating the abundance and size structure of an estuarine population of the sparid Pagrus auratus, using a towed camera during nocturnal periods of inactivity, and comparisons with conventional sampling techniques. Fish Res 82:150-161

Morrison M, Francis P, Parkinson D (2001). Trawl survey of snapper and associated species in the Hauraki Gulf, October 2000 (KAH0012). Final research report for Ministry of Fisheries Research Project INT2001/02, Ministry for Primary Industries, Wellington

> Palumbi SR, Sandifer PA, Allan JD, Beck MW and others (2009) Managing for ocean biodiversity to sustain marine ecosystem services. Front Ecol Environ 7:204-211

Parsons DA, Morrison MA, McKenzie JR, Hartill BW, Brian R, Francis RICC (2011) A fisheries perspective of behav- 
ioural variability: differences in movement behaviour and extraction rate of an exploited sparid, snapper (Pagrus auratus). Can J Fish Aquat Sci 68:632-642

Pikitch EK, Santora C, Babcock EA, Bakun A and others (2004) Ecosystem-based fishery management. Science 305:346-347

Pittman SJ, McAlpine CA (2003) Movement of fish and decapod crustaceans: process, theory and application. Adv Mar Biol 44:205-294

Pittman SJ, Christensen JD, Caldow C, Menza C, Monaco ME (2007) Predictive mapping of fish species richness across shallow-water seascapes in the Caribbean. Ecol Modell 204:9-21

Pittman SJ, Costa BM, Battista TA (2009) Using lidar bathymetry and boosted regression trees to predict the diversity and abundance of fish and corals. J Coast Res 53:27-38

R Development Core Team (2011) R: a language and environment for statistical computing. Version 2.12. R Foundation for Statistical Computing, Vienna

Ridgeway G (2006) 'gbm' generalized boosted regression models, R Package. Version 1.5. Accessed July 2011. http://cran.r-project.org/web/packages/gbm/

Ross PM, Thrush SF, Montgomery JC, Walker JW, Parsons DM (2007) Habitat complexity and predation risk determine juvenile snapper (Pagrus auratus) and goatfish (Upeneichthys lineatus) behaviour and distribution. Mar Freshw Res 58:1144-1151

Snelder TH, Leathwick JR, Dey KL, Rowden AA and others (2007) Development of an ecologic marine classification in the New Zealand region. Environ Manag 39:12-29

Stoner AW, Manderson JP, Pessutti JP (2001) Spatially explicit analysis of estuarine habitat for juvenile winter flounder: combining generalized additive models and geographic information systems. Mar Ecol Prog Ser 213:
253-271

Stoner AW, Spencer ML, Ryer CH (2007) Flatfish-habitat associations in Alaska nursery grounds: use of continuous video records for multi-scale spatial analysis. J Sea Res 57:137-150

Thrush SF, Dayton PK (2002) Disturbance to marine benthic habitats by trawling and dredging: implications for marine biodiversity. Annu Rev Ecol Syst 33:449-473

$>$ Thrush SF, Schultz D, Hewitt JE, Talley D (2002) Habitat structure in soft-sediment environments and abundance of juvenile snapper Pagrus auratus. Mar Ecol Prog Ser 245:273-280

> Thrush SF, Hewitt JE, Norkko A, Cummings VJ, Funnell GA (2003) Macrobenthic recovery processes following catastrophic sedimentation on estuarine sandflats. Ecol Appl $13: 1433-1455$

Usmar N (2009) Ontogeny and ecology of snapper (Pagrus auratus) in an estuary, the Mahurangi Harbour. PhD thesis, University of Auckland

> Valavanis VD, Pierce GJ, Zuur AF, Palialexis A, Saveliev A, Katara I, Wang J (2008) Modelling of essential fish habitat based on remote sensing, spatial analysis and GIS. Hydrobiologia 612:5-20

Warwick RM, Uncles RJ (1980) Distribution of benthic macrofauna associations in the Bristol Channel in relation to tidal stress. Mar Ecol Prog Ser 3:97-103

> Watling L, Norse EA (1998) Disturbance of the seabed by mobile fishing gear: a comparison to forest clearcutting. Conserv Biol 12:1180-1197

> Werner EE, Gilliam JF (1984) The ontogenetic niche and species interactions in size-structured populations. Annu Rev Ecol Syst 15:393-455

- Willis TJ, Parsons DM, Babcock RC (2001) Evidence for long-term site fidelity of snapper (Pagrus auratus) within a marine reserve. NZ J Mar Freshw Res 35:581-590 
Appendix 1. Mapped descriptions of (a) benthic diversity, (b) the number of burrows and (c) the number of pits encountered during the dropped underwater video surveys. (d) Recreational fishing intensities (boats $\mathrm{km}^{-2} \mathrm{yr}^{-1}$ ), as measured from aerial surveys in this area
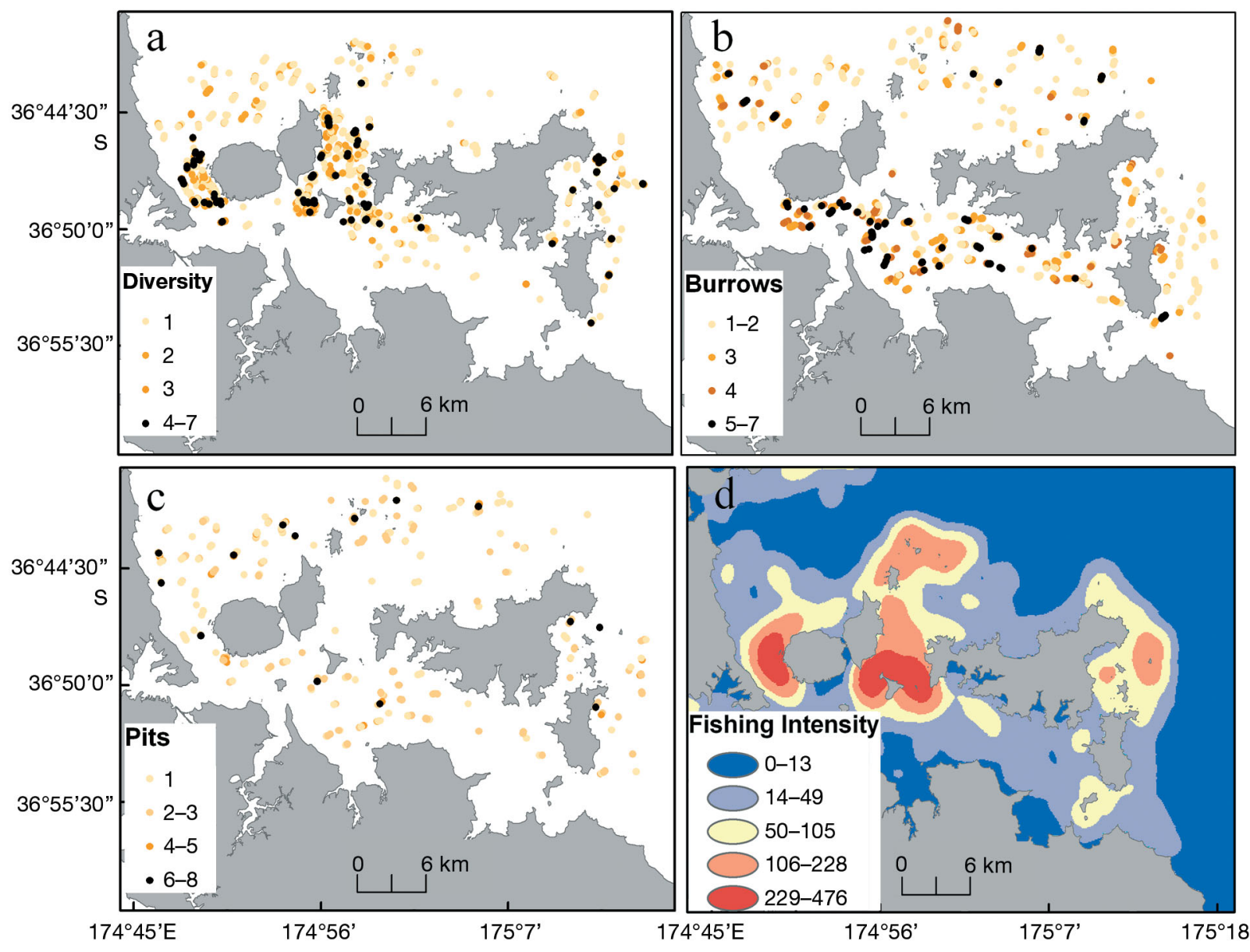

Editorial responsibility: Hans-Heinrich Janssen,

Submitted: February 8, 2012; Accepted: May 2, 2012 